\title{
MR-Neurography of the sural nerve in patients with hereditary amyloidosis
}

\author{
Jennifer Kollmer ${ }^{1 *}$, Markus Weiler ${ }^{2}$, Jan Purrucker ${ }^{2}$, Ute Hegenbart ${ }^{3}$, Stefan Schönland ${ }^{3}$, Christoph Kimmich ${ }^{3}$, \\ Martin Bendszus', Mirko Pham ${ }^{1}$ \\ From First European Congress on Hereditary ATTR amyloidosis \\ Paris, France. 2-3 November 2015
}

\section{Background}

Sural nerve biopsies are often performed in order to detect the underlying disease in patients suffering from unclear polyneuropathic symptoms. In transthyretin familial amyloid-polyneuropathy (TTR-FAP) the diagnostic value of invasive sural nerve biopsies is controversially discussed as it often lacks to detect amyloid deposits [Simmons et al, J Neurol Sci 1993]. As we recently reported, amyloid related nerve-injury in TTR-FAP can be unambiguously determined in large-caliber nerves (sciatic, tibial and common peroneal nerve) by applying high-resolution MR-Neurography (MRN) [Kollmer et al, Brain 2015]. However, the diagnostic yield of MRN of the small-caliber sural nerve, representing the target nerve specimen for biopsies, is still unclear and was subject to this investigation.

\section{Methods}

We prospectively enrolled 25 patients with manifest TTRFAP, 10 asymptomatic gene-carriers with confirmed mutations in the TTR-gene, and 40 age/gender-matched healthy volunteers. Besides detailed neurological and electrophysiological examinations in all patients, a sural nerve biopsy was obtained in 12/25 manifest TTR-FAP patients. All participants underwent the following high-resolution MRN protocol (3Tesla/Magnetom/TIM-TRIO/Siemens):1) axial 2D-T2-TSE-fs (TR/TE 5970/55ms, voxelsize $0.4 \times 0.3 \times 3.5 \mathrm{~mm}^{3}$ ); 2) axial 2D-dual-echo-TSE-fs (TR $5210 \mathrm{~ms}$, TE1/TE2 $12 / 73 \mathrm{~ms}$, voxel-size $0.4 \times 0.3 \times 3.5 \mathrm{~mm}^{3}$ ).

On each axial imaging slice the sural nerve was identified and manually segmented. After signal-normalization (histogram-based, comparison with control population), nervevoxels were statistically classified as nerve-lesion-voxels by

'University of Heidelberg, Department of Neuroradiology, 69120, Heidelberg, Germany

Full list of author information is available at the end of the article operator-independent, threshold-based segmentation. The apparent-T2-relaxation-time and proton-spin-density were calculated for all nerve-lesion-voxels.

\section{Results}

Sural nerve lesion-voxels were found to be significantly higher in manifest TTR-FAP vs. controls $(\mathrm{p}<0.0001)$, in asymptomatic gene-carriers vs. controls $(\mathrm{p}<0.0001)$ and in manifest TTR-FAP vs. asymptomatic carriers $(\mathrm{p}=0.0035)$. Wilcoxon rank-sum-test revealed with high statistical significance that proton-spin-density was higher in severely affected TTR-FAP patients $(\mathrm{p}<0.0001)$, in moderate TTR-FAP $(\mathrm{p}<0.0001)$ and also in asymptomatic gene-carriers $(\mathrm{p}=0.0003)$ compared to healthy controls. The apparent-T2-relaxation-time was significantly increased in symptomatic TTR-FAP $(\mathrm{p}<0.05)$ but not in asymptomatic gene-carriers $(\mathrm{p}=0.4286)$ compared to controls.

\section{Conclusion}

MRN of the sural nerve is a new, non-invasive and highly sensitive diagnostic tool, which can clearly differentiate between symptomatic TTR-FAP, asymptomatic gene-carrier status and healthy controls by evaluating nerve-lesion-voxels and proton-spin-density. Additional analyzes of the apparent-T2-relaxation-time can further confirm symptomatic disease. Results of this evaluation may have a strong impact for a better diagnostic interpretation of negative sural nerve biopsies.

\footnotetext{
Authors' details

'University of Heidelberg, Department of Neuroradiology, 69120, Heidelberg, Germany. ${ }^{2}$ University of Heidelberg, Department of Neurology, 69120, Heidelberg, Germany. ${ }^{3}$ University of Heidelberg, Medical Department $V$ (Amyloidosis Center), 69120, Heidelberg, Germany.
} 
Submit your next manuscript to BioMed Central and take full advantage of:

- Convenient online submission

- Thorough peer review

- No space constraints or color figure charges

- Immediate publication on acceptance

- Inclusion in PubMed, CAS, Scopus and Google Scholar

- Research which is freely available for redistribution 